ORNL/TM-2015/548

\title{
Status of Joining Thin Sheet and Thin Wall Tubes of $14 \mathrm{YWT}$
}

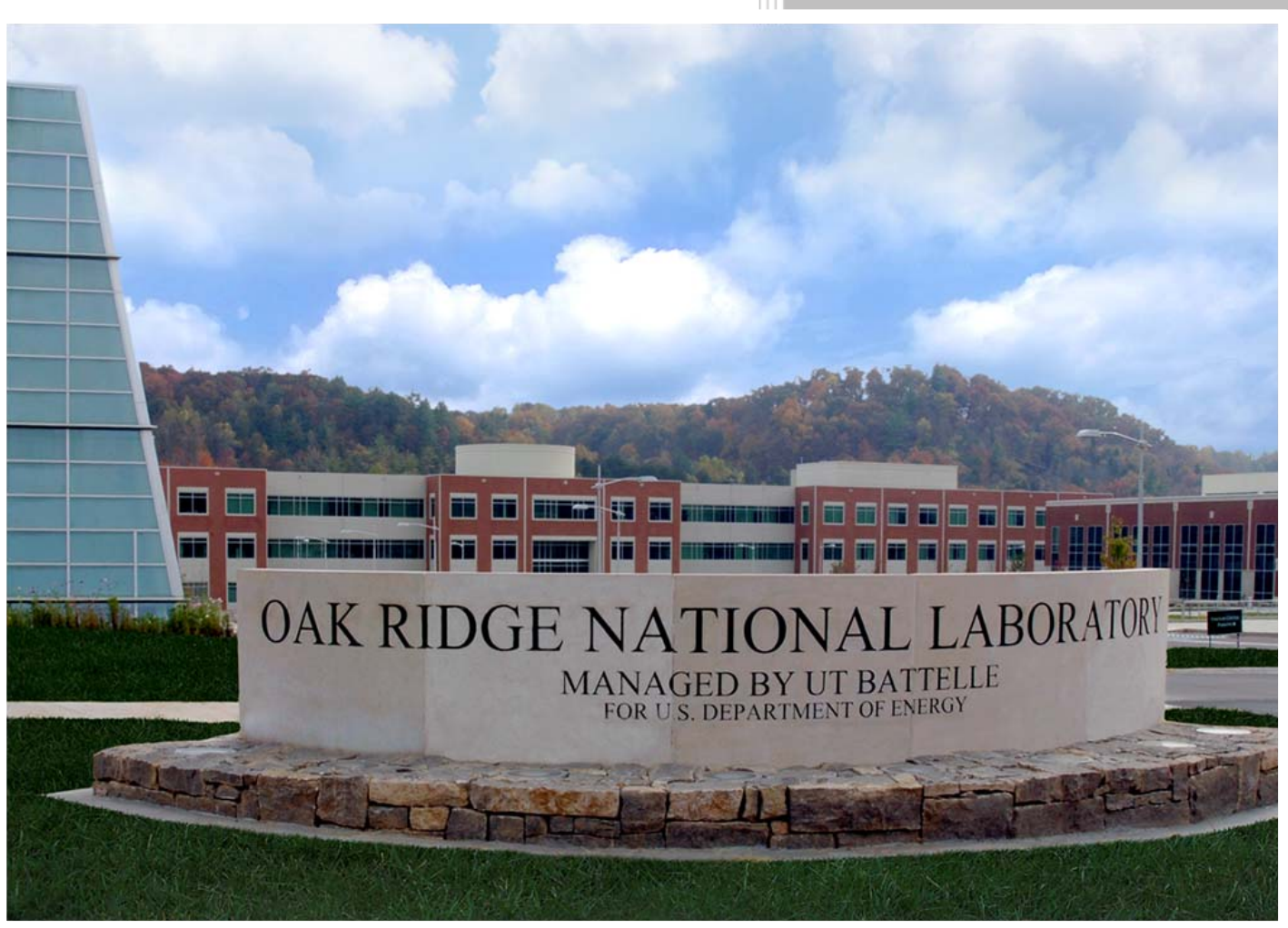

David T. Hoelzer Kinga A. Unocic Wei Tang Zhili Feng

September 18, 2015

Approved for public release. Distribution is unlimited. 


\section{DOCUMENT AVAILABILITY}

Reports produced after January 1, 1996, are generally available free via US Department of Energy (DOE) SciTech Connect.

Website http://www.osti.gov/scitech/

Reports produced before January 1, 1996, may be purchased by members of the public from the following source:

National Technical Information Service

5285 Port Royal Road

Springfield, VA 22161

Telephone 703-605-6000 (1-800-553-6847)

TDD 703-487-4639

Fax 703-605-6900

E-mail info@ntis.gov

Website http://www.ntis.gov/help/ordermethods.aspx

Reports are available to DOE employees, DOE contractors, Energy Technology Data Exchange representatives, and International Nuclear Information System representatives from the following source:

Office of Scientific and Technical Information

PO Box 62

Oak Ridge, TN 37831

Telephone 865-576-8401

Fax 865-576-5728

E-mail reports@osti.gov

Website http://www.osti.gov/contact.html

This report was prepared as an account of work sponsored by an agency of the United States Government. Neither the United States Government nor any agency thereof, nor any of their employees, makes any warranty, express or implied, or assumes any legal liability or responsibility for the accuracy, completeness, or usefulness of any information, apparatus, product, or process disclosed, or represents that its use would not infringe privately owned rights. Reference herein to any specific commercial product, process, or service by trade name, trademark, manufacturer, or otherwise, does not necessarily constitute or imply its endorsement, recommendation, or favoring by the United States Government or any agency thereof. The views and opinions of authors expressed herein do not necessarily state or reflect those of the United States Government or any agency thereof. 
Fuel Cycle Research and Development (FCRD) Program

\title{
STATUS OF JOINING THIN SHEET AND THIN WALL TUBES OF 14YWT
}

\author{
D.T. Hoelzer, K.A. Unocic, W. Tang and Z. Feng \\ Oak Ridge National Laboratory
}

Date Published: September 18, 2015

\author{
Prepared by \\ OAK RIDGE NATIONAL LABORATORY \\ Oak Ridge, Tennessee 37831-6283 \\ managed by \\ UT-BATTELLE, LLC \\ for the \\ US DEPARTMENT OF ENERGY \\ under contract DE-AC05-00OR22725
}





\section{CONTENTS}

Page

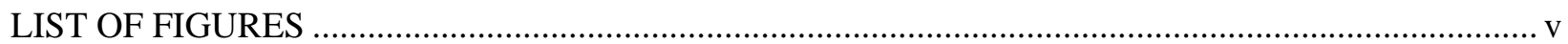

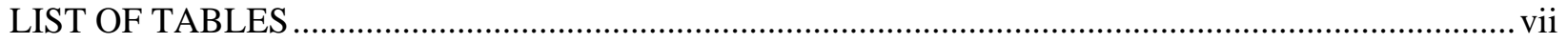

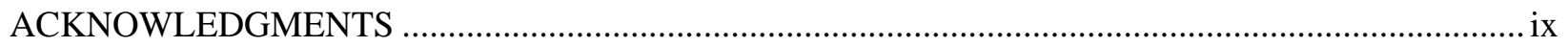

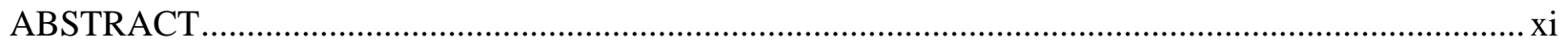

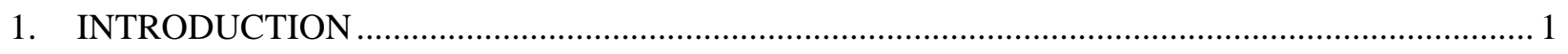

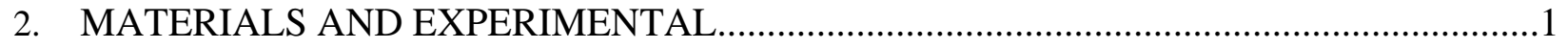

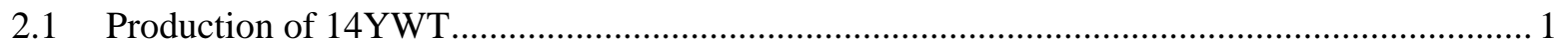

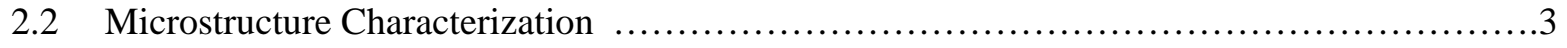

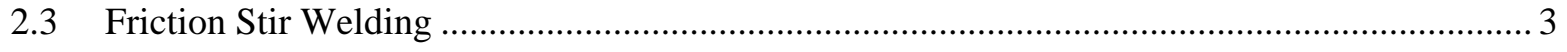

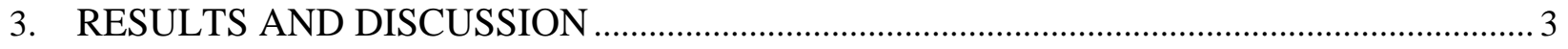

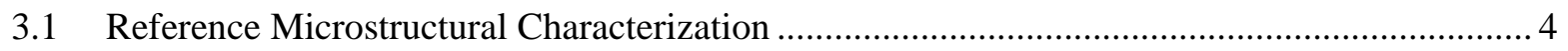

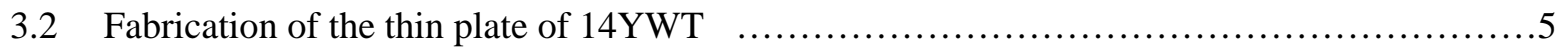

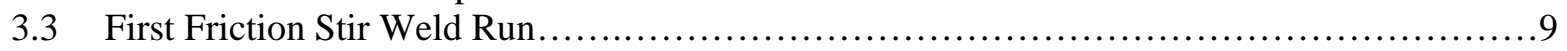

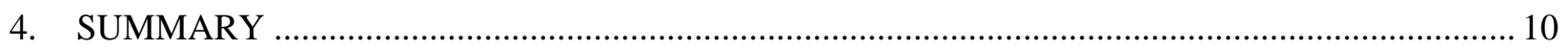

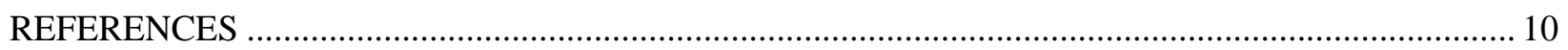





\section{LIST OF FIGURES}

Figure

Figure 1. Digital image showing the three extruded rectangular shaped rods of 14YWT (SM13

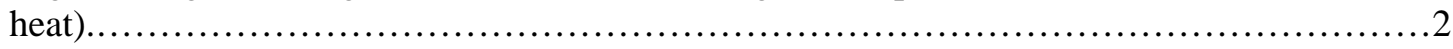

Figure 2. Digital images showing the 5 plates of 14YWT (SM13 heat) after cross-rolling to $\sim 1.06 \mathrm{~cm}$ thickness at $1000^{\circ} \mathrm{C}$. The images show (a) the edge view and (b) the top view of the 5 plates...................................................................

Figure 3. STEM micrographs showing the microstructure of 14YWT. (a) bright-field (BF) STEM image showing the ultra-fine grain structure and (b) high-angle annular dark field (HAADF) STEM image showing coarse particles (dark contrast) consistent with $\mathrm{Ti}(\mathrm{O}, \mathrm{C}, \mathrm{N})$ particles. Note: the HAADF STEM image is shifted down $\sim 1 \mu \mathrm{m}$ relative to the BF STEM image............................................................

Figure 4. Grain size distribution obtained from EBSD analysis of 14YWT (SM13 heat). ..............5

Figure 5 HAADF STEM micrograph showing the high number density of 2-5 nm size nanoclusters observed within the grain in 14YWT (SM13 heat). ........................

Figure 6. Digital images showing the results of the first rolling attempt to reduce the thickness of (a) the $1.06 \mathrm{~cm}$ thick plate to (b) the $0.5 \mathrm{~cm}$ thick plate of 14YWT showing the orientation of the cut. ...............................................................

Figure 7. Digital image illustrating the orientations for cutting the $0.5 \mathrm{~cm}$ thick plate of 14YWT and the extrusion and cross rolling directions...................................

Figure 8. Digital image showing the results of the second rolling attempt to reduce the thickness of the $0.5 \mathrm{~cm}$ thick plate (right side of image) to $0.22 \mathrm{~cm}$ thick plate (left

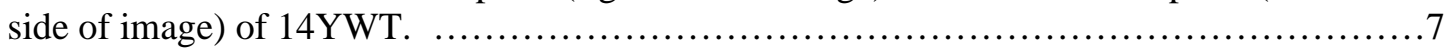

Figure 9. Digital image illustrating the orientation for cutting the $0.22 \mathrm{~cm}$ thick plate of 14YWT and the extrusion and cross rolling directions. ..................................

Figure 10. Digital image showing the results of the third rolling attempt to reduce the thickness of the $0.22 \mathrm{~cm}$ thick plate (left side of image) to $0.1 \mathrm{~cm}$ thick plate (right side of image) of $14 \mathrm{YWT}$.

Figure 11. Digital images (a) illustrating the orientations for cutting the $0.1 \mathrm{~cm}$ thick plate of 14YWT and the extrusion and cross rolling directions and (b) the cut $0.1 \mathrm{~cm}$ thick plate used in the first FSW attempt. ....

Figure 12. Digital images showing the bead-on-plate weld zone obtained by FSW on the $0.1 \mathrm{~cm}$ thick plate of 14YWT. The image in (a) shows the top view and in (b) the near edge view of the thin plate. Note: the arrow in Fig. 12b shows the location of the bead-onplate weld zone. 



\section{LIST OF TABLES}

\section{Table}

Page

Table 1. The dimensions of the 5 plates of 14YWT (SM14 heat) ........................................................ 3

Table 2. Chemical analysis of the extruded and hot rolled plate of 14YWT (SM13 heat)........................ 3 



\section{ACKNOWLEDGMENTS}

This research was sponsored by the U.S. Department of Energy, Office of Nuclear Energy, for the Fuel Cycle Research and Development (FCRD) program.

The authors are grateful to David Harper and Gregory Cox of ORNL for assistance in processing and fabrication of the ODS materials. The authors want to also acknowledge Yukinori Yamamoto for reviewing the manuscript. 



\begin{abstract}
Beginning this fiscal year, the FCRD research project initiated an investigation on joining thin sections of the advanced ODS 14YWT ferritic alloy. Friction stir welding (FSW) was investigated as a method to join thin plate and tubing of 14YWT since it is a solid state joining method that has been shown in past studies to be a promising method for joining plates of ODS alloys, such as 14YWT. However, this study will attempt to be the first to demonstrate if FSW can successfully join thin plates and thin wall tubing of 14YWT. In the first FSW attempt, a $1.06 \mathrm{~cm}$ thick plate of 14YWT (SM13 heat) was successfully rolled at $1000^{\circ} \mathrm{C}$ to the target thickness of $0.1 \mathrm{~cm}$ with no edge cracking. This achievement is a highlight since previous attempts to roll 14YWT plates have resulted in extensive cracking. For the FSW run, a pin tool being developed by the ORNL FSW Process Development effort was used. The first FSW run successfully produced a bead-on-plate weld in the $0.1 \mathrm{~cm}$ thick plate. The quality of the weld zone appears very good with no evidence of large defects such as cavities. The microstructural characterization study of the bead-on-plate weld zone has been initiated to compare the results of the microstructure analysis with those obtained in the reference microstructural analysis of the 14YWT (SM13 heat) that showed ultra-fine grain size of $0.43 \mu \mathrm{m}$ and a high number density of $\sim 2-5 \mathrm{~nm}$ sizes oxygen-enriched nanoclusters.
\end{abstract}




\section{INTRODUCTION}

The advanced oxide dispersion strengthened (ODS) 14YWT ferritic alloy is currently being developed for fuel cladding in fast reactor technologies. This alloy possesses remarkable resistance to high-temperature creep and microstructural degradation to high-dose irradiations, as demonstrated by high-dose ion irradiation studies. However, joining plates of advanced ODS ferritic alloys presents serious challenges that historically have hindered their acceptance in many structural applications. The highly tailored microstructure of 14YWT consisting of ultra-fine grain size and high number density of nano-size Ti-, Yand O-enriched clusters, or nanoclusters (NC) are responsible for the high-temperature strength and radiation tolerance, but will make joining even more challenging. Furthermore, the goal of this study is to ultimately demonstrate if thin wall fuel clad tubing of 14YWT can be successfully be joined, which introduces several new complications to joining.

Beginning this year, the research for joining thin sections of 14YWT focused on the friction stir welding (FSW) approach. This method is a solid-state joining technique that was originally developed within the aluminum industry in 1991 [1]. The concept of FSW involves plunging a specially designed tool into the work piece that rotates at high speeds traveling along the seam between the work pieces and joining by solid-state mixing. Heat produced by friction from contact between the rotating tool and work pieces allows material to flow around the tool during the translation of the rotating tool. As the tool travels along the seam, a cavity forms at the rear that becomes filled with material redistributed by the rotating tool to form the weld. The redistribution process causes the material to experiences extreme levels of plastic deformation and thermal exposure that, in turn, can have a significant effect on microstructural changes in the weld zone. A recent review of the friction stir welding and related friction stir processing methods has been published [2]. Recently there have been several FSW studies on joining ODS alloys that have demonstrated joints could be produced with INCO MA957 FA [3,4], INCO MA956 [5,6], ODS Eurofer 97 TMS [7], Plansee PM2000 FA [8] and 14YWT [9]. However, there have been no studies on joining thin plates of ODS alloys. Therefore, the objective of this study initiated this fiscal year is to develop the FSW method for joining $\sim 0.5 \mathrm{~mm}$ thick sheets of 14YWT and, depending on the success, followed by joining two thin wall $(0.5 \mathrm{~mm})$ tubes with a circumference butt joint. For the FSW joining demonstration, the first FSW runs will be conducted on $\sim 1 \mathrm{~mm}$ thick sheet of 14YWT, but this depended on whether hot rolling a thick plate of $14 \mathrm{YWT}$ to $\sim 1 \mathrm{~mm}$ or less could be done successfully without forming edge cracks.

\section{MATERIALS AND EXPERIMENTAL}

\subsection{Production of $14 Y W T$}

The plate of 14YWT (SM13) used in the FSW study was originally from a set of 5 plates that were produced for the IAEA Coordinated Research Project (CRP) on Benchmarking of Structural Materials Pre-Selected for Advanced Nuclear Reactors at the ENEA Headquarters in Rome, Italy. The duration of the CRP was from 2012-2014. Four of the plates were supplied to the CRP for round-robin characterization studies of mechanical properties and microstructures at participating international research institutes. The fifth plate was retained at ORNL for research activities in the FCRD program.

The production of the 5 plates of 14YWT (SM13 heat; hereafter referred to as 14YWT) occurred in 2012. A total of 6 ball mill runs were conducted with $1 \mathrm{~kg}$ of Fe-14Cr-3W-0.4Ti (Special Metals) and $0.3 \% \mathrm{Y}_{2} \mathrm{O}_{3}$ powder using the high kinetic energy CM08 Simoloyer at ORNL. Each ball milling run was for $40 \mathrm{~h}$ with the powder exposed to Ar cover gas. A total of $\sim 5.4 \mathrm{~kg}$ of ball milled powder was generated in the 6 ball mill runs. The 6 lots of ball milled powder were combined and blended by tumbling. Three 4 inch diameter mild steel cans were fabricated and filled with the $\sim 5.4 \mathrm{~kg}$ of ball milled powder. The three cans were degassed at $400^{\circ} \mathrm{C}$, sealed, heated to $850{ }^{\circ} \mathrm{C}$ for $1 \mathrm{~h}$ and then extruded through a $2.5 \mathrm{in}$. wide $\mathrm{x}$ 1.2 in. high die into rectangular-shaped bars shown in Figure 1. After the bars were cut to reveal the ODS 
section, the length of the 3 bars containing the ODS 14YWT-SM13 were $8.5,8.5$ and 6 inches. The two 8.5 inch long bars were cut in half and all 5 bars were annealed at $1000^{\circ} \mathrm{C}$ for $1 \mathrm{~h}$ and then cross rolled to $50 \%$ reduction in thickness (RIT) at $1000^{\circ} \mathrm{C}$ to produce the 5 plates shown in Figure 2. After the mild steel can was machined from the plates, the dimension of each plate was measured and is shown in Table 1. The plate that was retained at ORNL was 5869 Plate 1 (Fig. 2b). This plate had a thickness after 50\% RIT of $1.06 \mathrm{~cm}$ (Table 1). The chemical analysis of the 14YWT plate is shown in Table 2. The $\mathrm{O}$ and $\mathrm{N}$ levels were slightly high, but were reasonable.

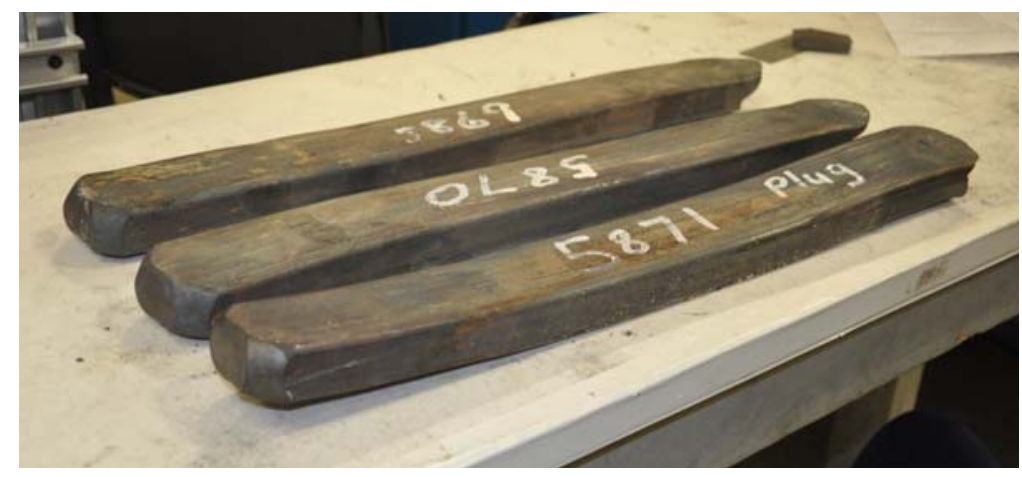

Figure 1. Digital image showing the three extruded rectangular shaped rods of 14YWT (SM13 heat).

(a)

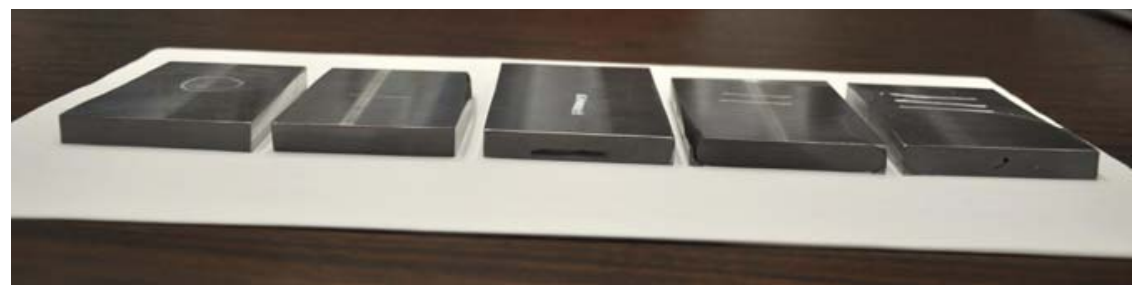

(b)

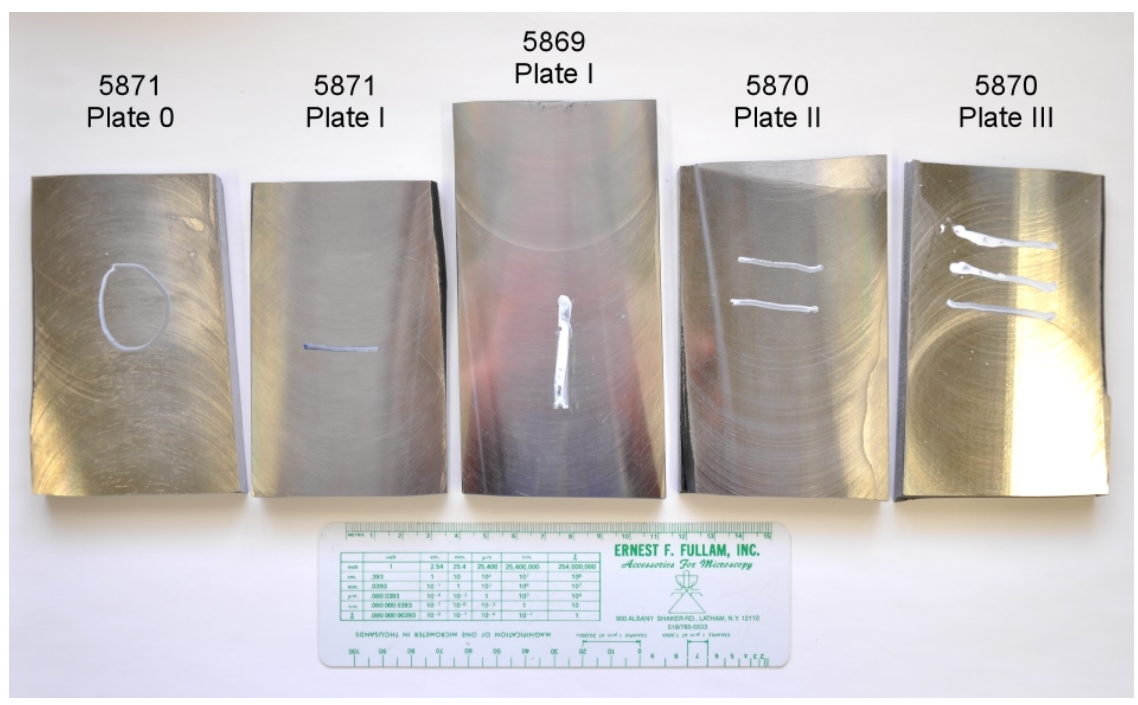

Figure 2. Digital images showing the 5 plates of 14YWT (SM13 heat) after cross-rolling to $1.06 \mathrm{~cm}$ thickness at $1000^{\circ} \mathrm{C}$. The images show (a) the edge view and (b) the top view of the 5 plates.

Table 1. The dimensions of the 5 plates of 14YWT (SM13 heat). 


\begin{tabular}{|c|c|c|c|c|c|}
\hline \multicolumn{6}{|c|}{ 14YWT-SM13: Cross rolled at $1000^{\circ} \mathrm{C}$ to $50 \%$ reduction in thickness } \\
\hline \multirow{2}{*}{ Extrusion ID } & \multirow{2}{*}{ Plate ID } & \multicolumn{3}{|c|}{ Dimension (cm) } & \multirow{2}{*}{$\begin{array}{l}\text { Weight }(\mathrm{g}) \\
(+/-0.05 \mathrm{~g})\end{array}$} \\
\hline & & Width & Length & Thickness & \\
\hline 5869 & I & 7.04 & 13.74 & 1.06 & 797.18 \\
\hline 5870 & II & 6.77 & 11.51 & 1.09 & 701.40 \\
\hline 5870 & III & 6.62 & 11.40 & 1.10 & 671.00 \\
\hline 5871 & 0 & $6.35-7.17$ & 11.03 & 1.10 & 651.06 \\
\hline 5871 & 1 & $6.30-6.76$ & 10.81 & 1.14 & 635.50 \\
\hline
\end{tabular}

Table 2. Chemical analysis of the extruded and hot rolled plate of 14YWT (SM13 heat).

\begin{tabular}{|c|c|c|c|c|c|c|c|c|}
\hline Elements & Fe & Cr & W & Ti & Y & O & C & N \\
\hline Wt. \% & Bal. & 14.300 & 2.320 & 0.270 & 0.190 & 0.177 & 0.024 & 0.099 \\
\hline At. \% & Bal. & 15.313 & 0.703 & 0.314 & 0.119 & 0.616 & 0.111 & 0.394 \\
\hline
\end{tabular}

\subsection{Microstructure Characterization}

The reference microstrsuctural characaterization study was conducted on the $1.06 \mathrm{~cm}$ thick plate shown in Figure 2. A specimen was cut from the plate, mounted and polished using metallographic procedures. The polished sample was examined in the JEOL 6500F Scanning Electron Microscope (SEM) using electron back scattered diffraction (EBSD) for grain size and texture anlaysis. A specimen for TEM analsysis was prepared from the polished sample using the focus ion beam (FIB) in-situ lift-out technique in the Hitachi NB5000 FIB-SEM. The thinned specimen was examined using the JEOL 2200FS-AC Field Emission Gun (FEG) scanning transmission electron microscope (STEM) operated at 200kV with a corrected probe (using CEOS Cs-Corrector) of 0.7 $\AA$ resolution and Bruker XFlash ${ }^{\circledR} 6 \mid 30$ SDD system.

\subsection{Friction stir welding}

The first FSW experiment will be performed using a bead-on-plate approach using a Polycrystalline Cubic Boron Nitride (PCBN) pin tool. Details about design of the pin tool are proprietary to the ORNL FSW Process Development effort and cannot be described in this report. Neither can the parameters used in the first trial FSW run other than the pin tool rotation speed was several hundred revolutions per minute (rpm). However, it should be pointed out that the design must allow for generating sufficient frictional heat to cause proper deformation and flow of material during the FSW run. The rotating pin tool traveled parallel to the extrusion direction of the 14YWT thin plate.

\section{RESULTS AND DISCUSSION}

A microstructural characterization study of the cross-rolled plate was conducted to establish the reference microstructure of 14YWT for comparison after the bead-on-plate FSW run is performed. If successful, then a specimen will be extracted from the stir zone of the FSW material for examination by SEM followed by preparation of a lift-out/FIB specimen for TEM analysis to compare with the reference microstructure. 


\subsection{Reference microstructural characterization}

The microstructure of 14YWT observed by STEM imaging is shown in Figure 3. The bright-field (BF) STEM micrograph (Fig. 3a) shows mostly small grains with low grain aspect ratio. However, a few grains appear elongated over $1 \mathrm{~mm}$ in length parallel to the extrusion direction (left to right in the micrograph). The high angle annular dark field (HAADF) STEM micrograph (Fig. 3b) shows a low number density of particles that were in the size range of $\sim 20-60 \mathrm{~nm}$ in diameter. These particles appear dark in the HAADF STEM micrograph indicating their composition is based on low atomic number (Z) elements. These particles are most likely $\mathrm{Ti}(\mathrm{O}, \mathrm{C}, \mathrm{N})$ based on past characterization studies of 14YWT. From the EBSD analysis, the grain size distribution is shown in Figure 4. The average grain size was determined to be $0.43 \mu \mathrm{m}$, which is typical of past heats of 14YWT.

(a)

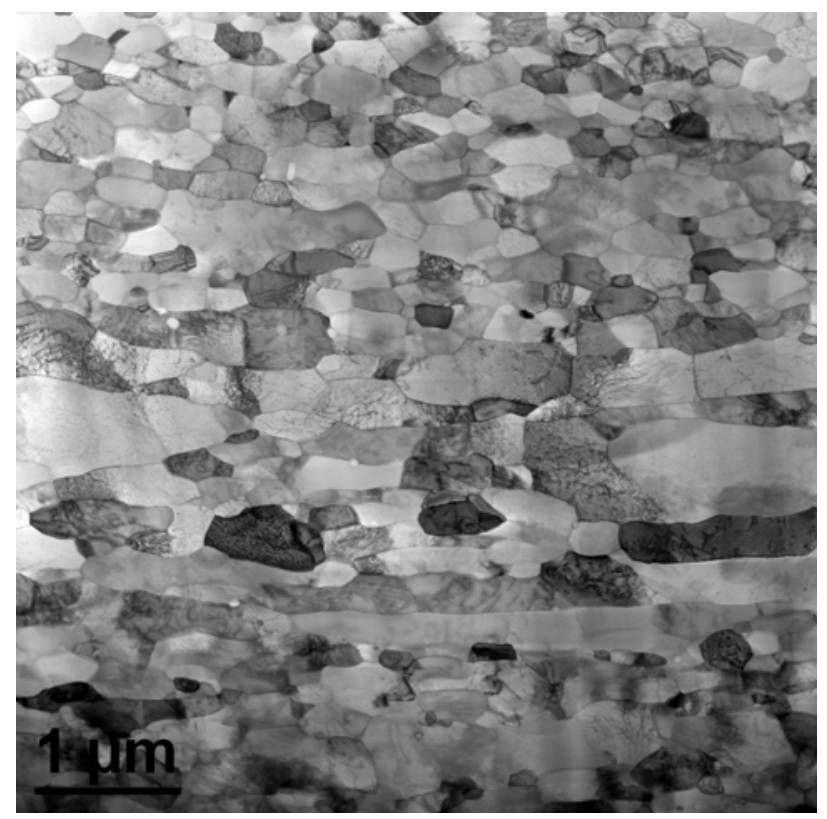

(b)

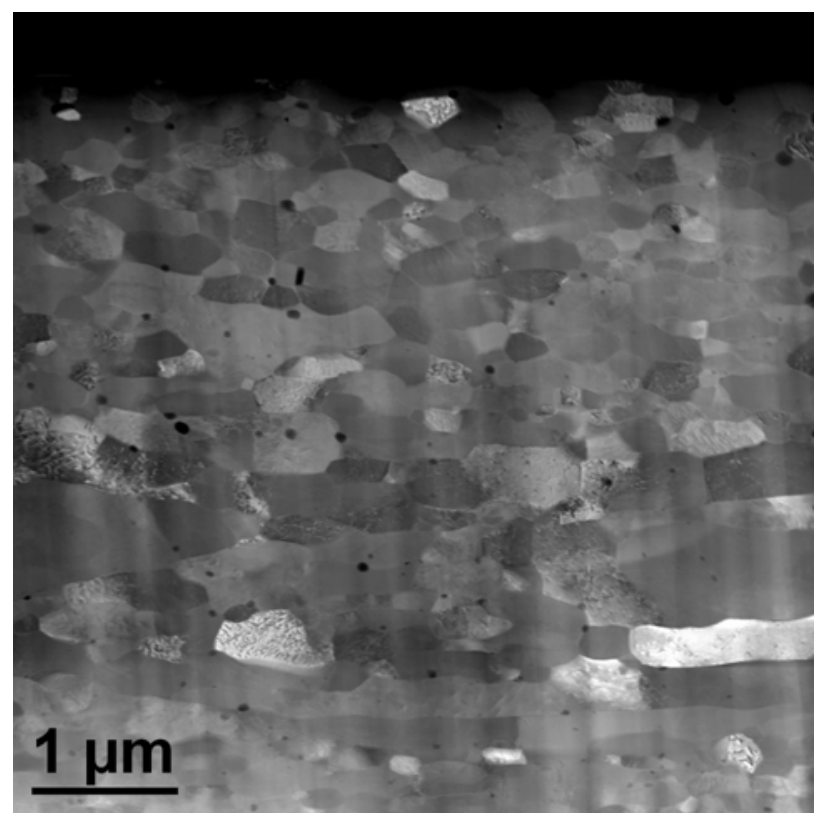

Figure 3. STEM micrographs showing the microstructure of 14YWT. (a) bright-field (BF) STEM image showing the ultra-fine grain structure and (b) high-angle annular dark field (HAADF) STEM image showing coarse particles (dark contrast) consistent with Ti(O,C,N) particles. Note: the HAADF STEM image is shifted down $\sim 1 \mu \mathrm{m}$ relative to the BF STEM image.

The microstructure of 14YWT observed by HAADF STEM imaging at high magnification is shown in Figure 5. The micrograph shows the presence of a high number density (qualitative assessment) of particles within the grain. The dark contrast observed for the particles is consistent with oxygen-enriched nanoclusters imaged by Z-contrast in HAADF STEM. The size of the nanoclusters was measured by placing a line intensity histogram on the particle in Digital Micrograph (Gatan software) and determining the size at full width at half maximum (FWHM). Using this method, a majority of the nanoclusters observed in Figure 5 were within the size range of $2-5 \mathrm{~nm}$. The sizes of two nanoclusters shown with arrows in the figure were determined to be $2.5 \mathrm{~nm}$ and $5.5 \mathrm{~nm}$, with the latter being just above the size range. This size range is also typical with that determined for nanoclusters in past heats of 14YWT. 


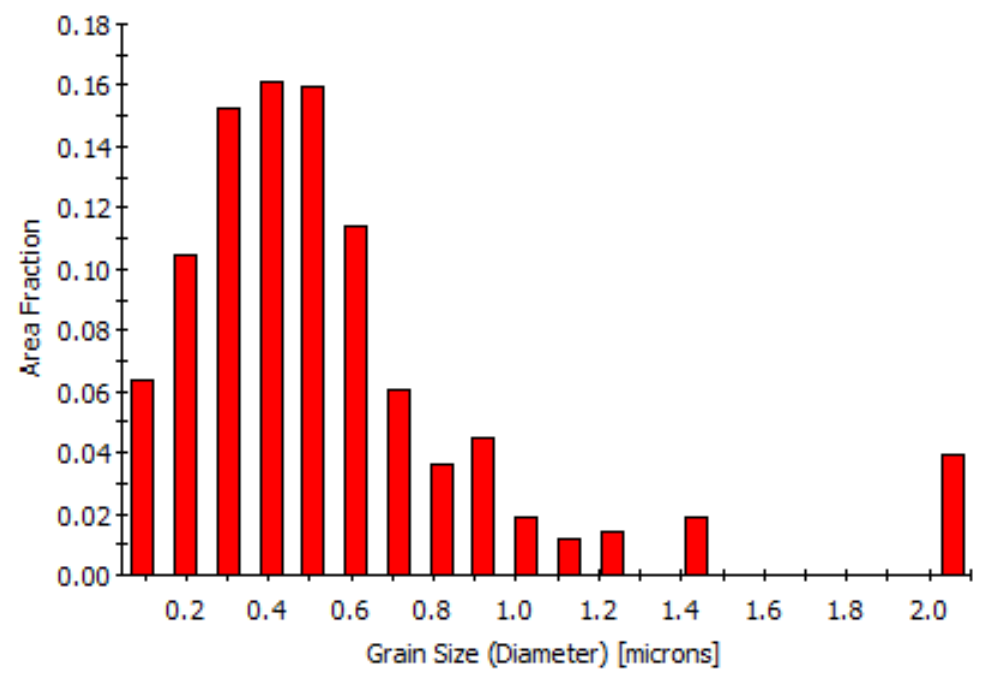

Figure 4. Grain size distribution obtained from EBSD analysis of 14YWT (SM13 heat).

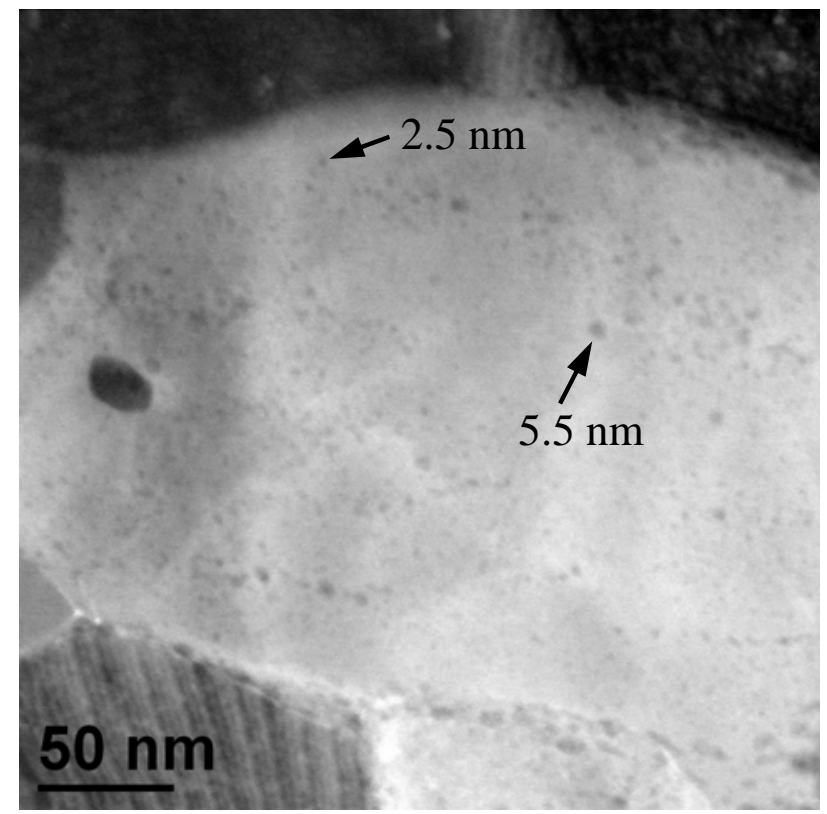

Figure 5. HAADF STEM micrograph showing the high number density of 2-5 nm size nanoclusters observed within the grain in 14YWT (SM13 heat).

\subsection{Fabrication of the thin plate of 14YWT}

The fabrication study for producing a thin plate of 14YWT was performed with the $1.06 \mathrm{~cm}$ thick plate (5869) of 14YWT. The first rolling attempt was conducted by heating the $1.06 \mathrm{~cm}$ thick plate to $1000^{\circ} \mathrm{C}$ and cross rolling (perpendicular relative to the extrusion direction) to $0.5 \mathrm{~cm}$ thickness, which was $54 \%$ reduction in thickness (RIT). Figure 6 shows the starting plate (Fig. 6a) and the 54\% cross rolled plate. Inspection of the rolled plate showed no edge cracks formed. The procedure that was used in this rolling attempt and all remaining attempts was to cut the rolled plate in half as illustrated with the dotted line in 
Figure 6b. One half of the cut plate was rolled in the next attempt, with the other half saved for either a second rolling attempt or for microstructural analysis in the future.

(a)

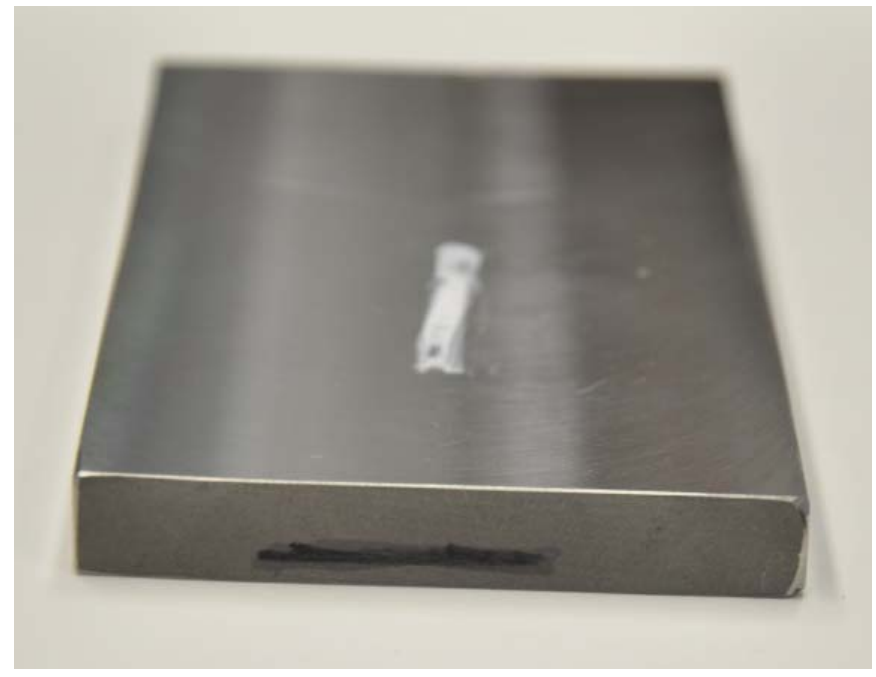

(b)

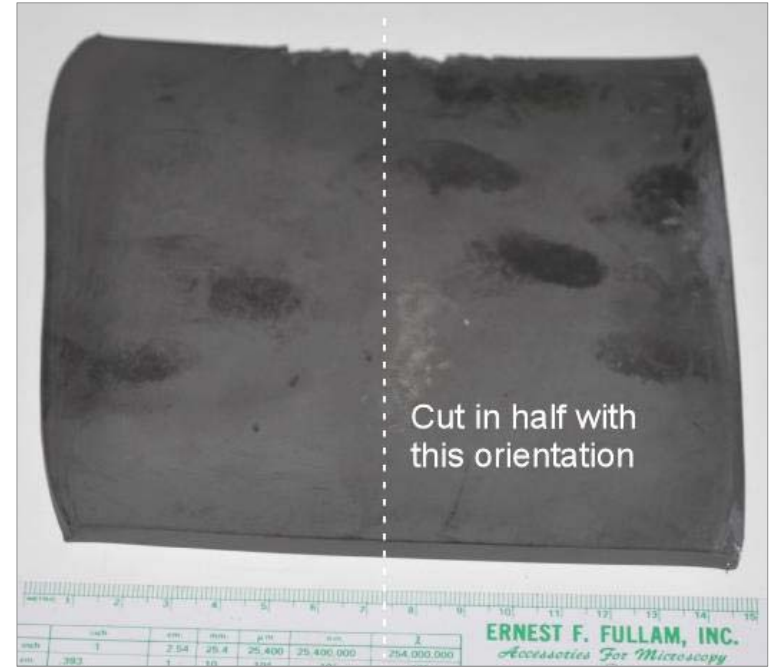

Figure 6. Digital images showing the results of the first rolling attempt to reduce the thickness of (a) the $1.06 \mathrm{~cm}$ thick plate to (b) the $0.5 \mathrm{~cm}$ thick plate of 14YWT showing the orientation of the cut.

After cutting the $0.5 \mathrm{~cm}$ thick plate in half, one half (left side in Fig. 6b) was used in a Friction Stir Welding study for a different research program while the other half (right side in Fig. 6b) was cut in half for the next rolling attempt. Figure 7 illustrates the orientation of the cut and the orientation of extrusion and cross rolling directions. As before, one side (right side in Fig. 7) was used in the next rolling attempt and the other side (left side in Fig. 7) was saved.

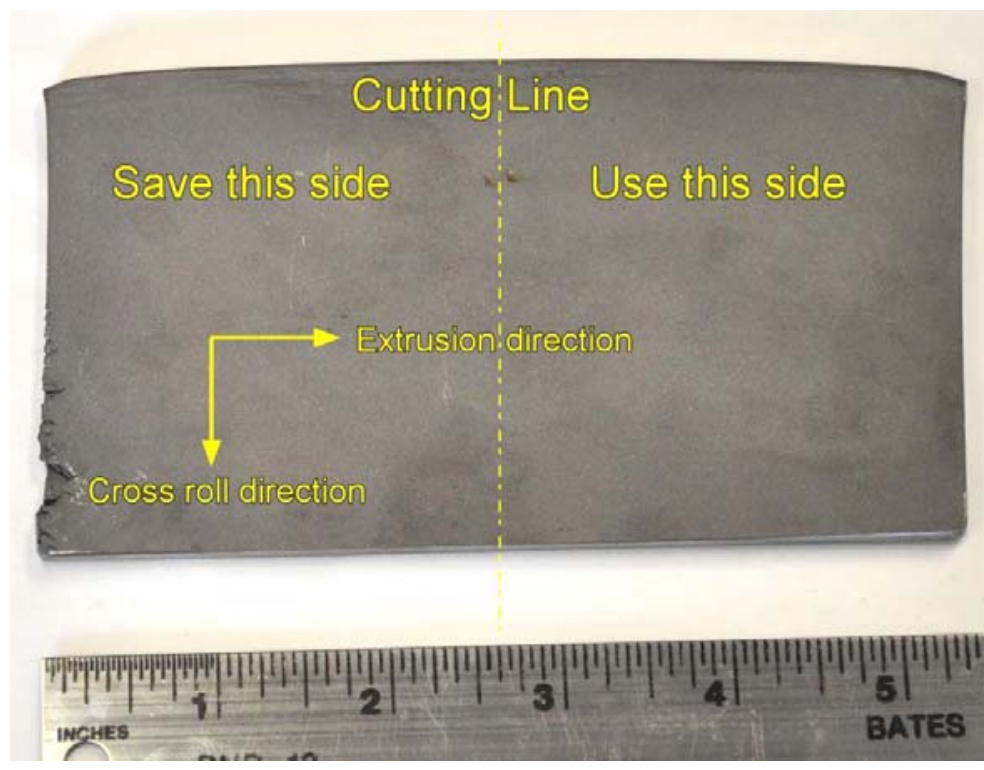

Figure 7. Digital image illustrating the orientations for cutting the $0.5 \mathrm{~cm}$ thick plate of $14 \mathrm{YWT}$ and the extrusion and cross rolling directions. 
The second attempt involved rolling the $0.5 \mathrm{~cm}$ thick plate parallel to the extrusion direction to $0.22 \mathrm{~cm}$ thick plate at $1000^{\circ} \mathrm{C}$. Figure 8 shows the $0.5 \mathrm{~cm}$ thick plate (right side of image) that was saved and the $0.22 \mathrm{~cm}$ thick plate of 14YWT (left side of image) after rolling. This rolling resulted in 54\% RIT with no edge cracks forming. The result showing no edge crack formation was significant since edge cracking was so prevalent in a previous rolling experiment on a plate of 14YWT (SM11 heat) that further rolling of the plate was terminated after obtaining a thickness of $0.3 \mathrm{~cm}$.

As before, the $0.22 \mathrm{~cm}$ thick plate was cut in half as illustrated in Figure 9. With reference to this figure, the left half of the plate was saved while the right half of the plate was used in the next rolling attempt. In the third rolling attempt, the $0.22 \mathrm{~cm}$ thick plate was heated to $1000^{\circ} \mathrm{C}$ followed by cross rolling to $0.1 \mathrm{~cm}$ thickness, or 54\% RIT. Inspection showed no edge cracks were present, which was significant since the total amount of rolling deformation from the initial thickness of the extruded bar $(\sim 21.2 \mathrm{~cm})$ to the final thickness of $0.1 \mathrm{~cm}$ was $95.3 \%$ RIT. While rolling was done at $1000^{\circ} \mathrm{C}$, the results of this rolling experiment demonstrates that the improved processing conditions developed in the FCRD program most likely contributed to the improvement in fabricability of 14YWT. In this case, the 14YWT (SM13 heat) contained a lower interstitial $\mathrm{O}, \mathrm{C}$ and $\mathrm{N}$ concentration levels compared to many of the past heats of $14 \mathrm{YWT}$ that have been produced at ORNL.

For the first FSW run, the $0.1 \mathrm{~cm}$ thick plate of 14YWT was cut in half as shown in Figure 11. The orientation of the cut is illustrated in Figure 11a and the plate used in the FSW run is shown in Figure 11b. This plate was sand blasted to remove as much of the surface oxide scale as possible before the FSW attempt.

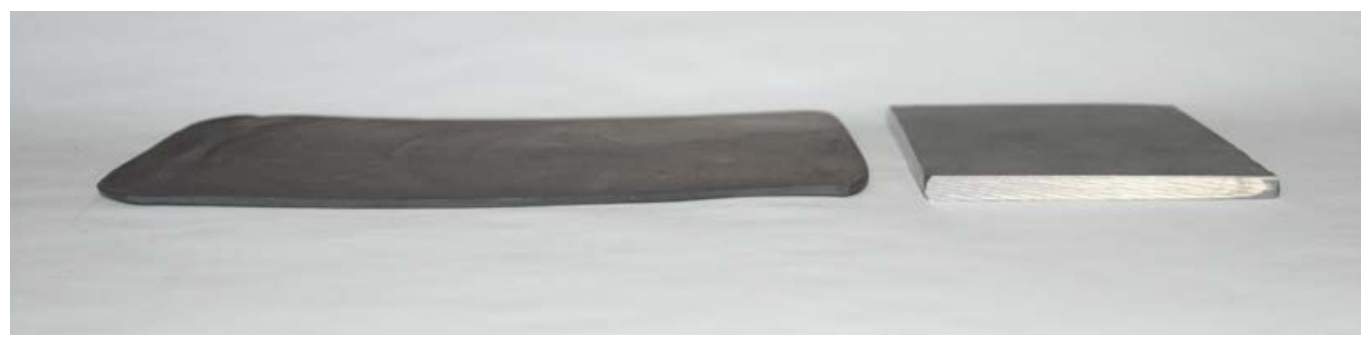

Figure 8. Digital image showing the results of the second rolling attempt to reduce the thickness of the 0.5 $\mathrm{cm}$ thick plate (right side of image) to $0.22 \mathrm{~cm}$ thick plate (left side of image) of 14YWT.

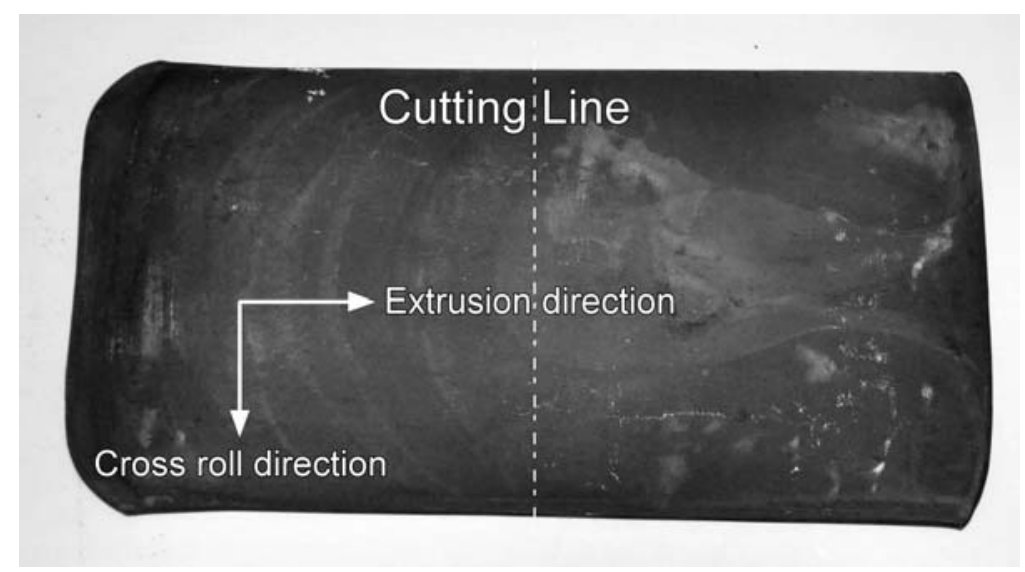

Figure 9. Digital image illustrating the orientation for cutting the $0.22 \mathrm{~cm}$ thick plate of $14 \mathrm{YWT}$ and the extrusion and cross rolling directions. 


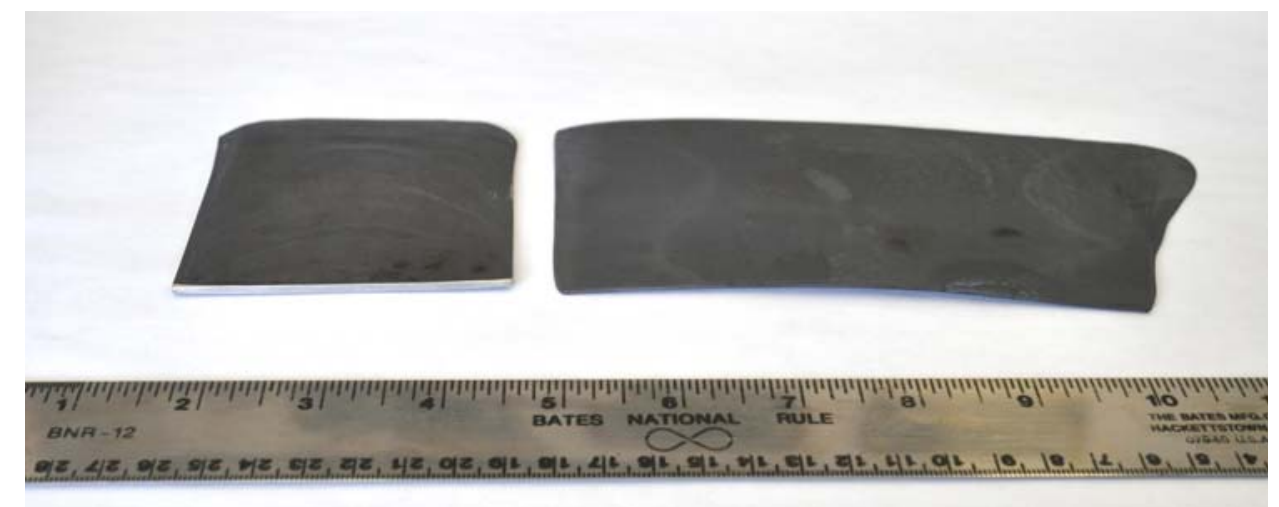

Figure 10. Digital image showing the results of the third rolling attempt to reduce the thickness of the $0.22 \mathrm{~cm}$ thick plate (left side of image) to $0.1 \mathrm{~cm}$ thick plate (right side of image) of 14YWT.

(a)

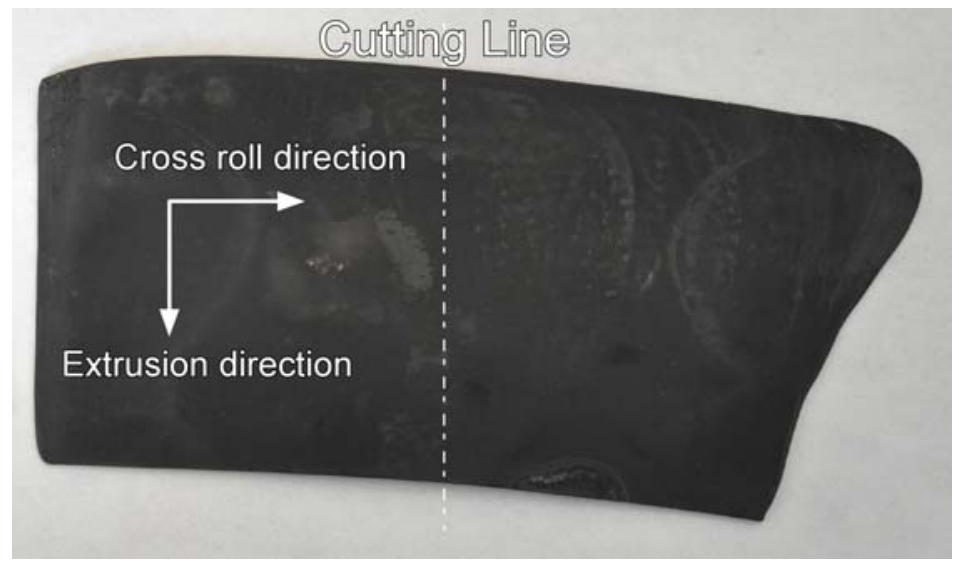

(b)

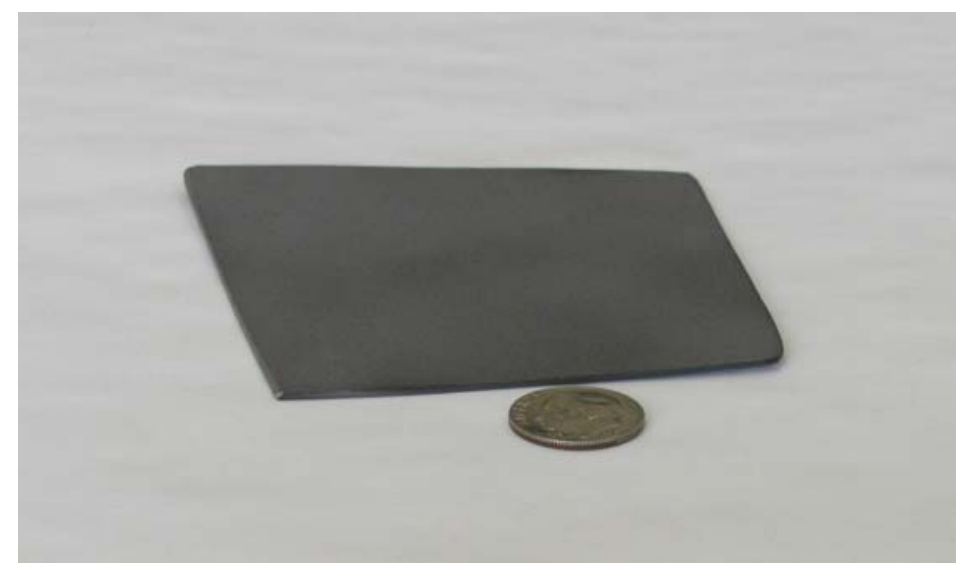

Figure 11. Digital images (a) illustrating the orientations for cutting the $0.1 \mathrm{~cm}$ thick plate of $14 \mathrm{YWT}$ and the extrusion and cross rolling directions and (b) the cut $0.1 \mathrm{~cm}$ thick plate used in the first FSW attempt. 


\subsection{First Friction Stir Weld Run}

The results of the first FSW attempt using a bead-on-plate approach on the $0.1 \mathrm{~cm}$ thick plate of 14YWT is shown in Figure 12. The $0.1 \mathrm{~cm}$ thick plate was cut in half which accounts for the abrupt cut-off side (top side) of the FSW bead-on-plate shown in Figure 12a. Figure 12b shows the $0.1 \mathrm{~cm}$ thick plate nearly edge-on. This view demonstrates that the FSW bead-on-plate weld zone (denoted by arrow) is nearly continuous in thickness with the surrounding unaffected plate. From optical inspection, the bead-on-plate weld zone shows good mixing with no evidence of defects such as cavities. The swirl flow pattern that is observed for the bead-on-plate weld is commonly observed with FSW joints, which indicates that sufficient heat from friction generated between the rotating and traveling shoulder and pin tool with the 14YWT plate caused 14YWT material to be redistributed from the front to the rear of the bead-on-plate weld. This first FSW attempt is novel, since there have been no studies in the published literature that have attempted FSW on thin plates of ODS alloys.

(a)

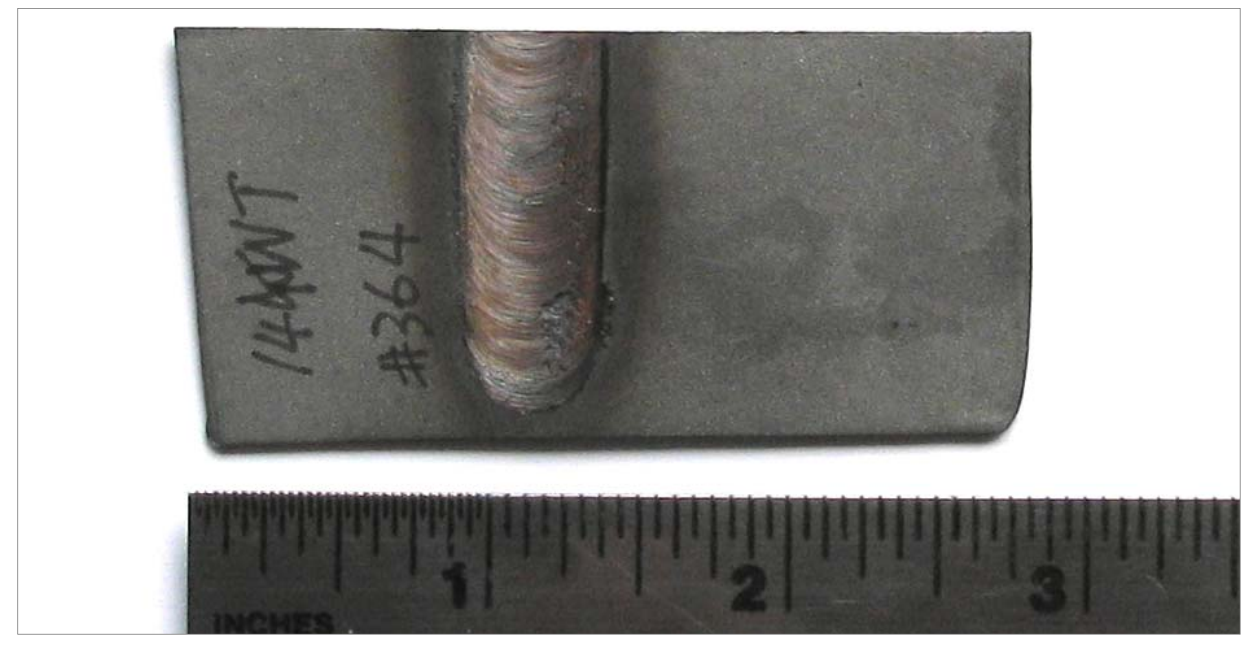

(b)

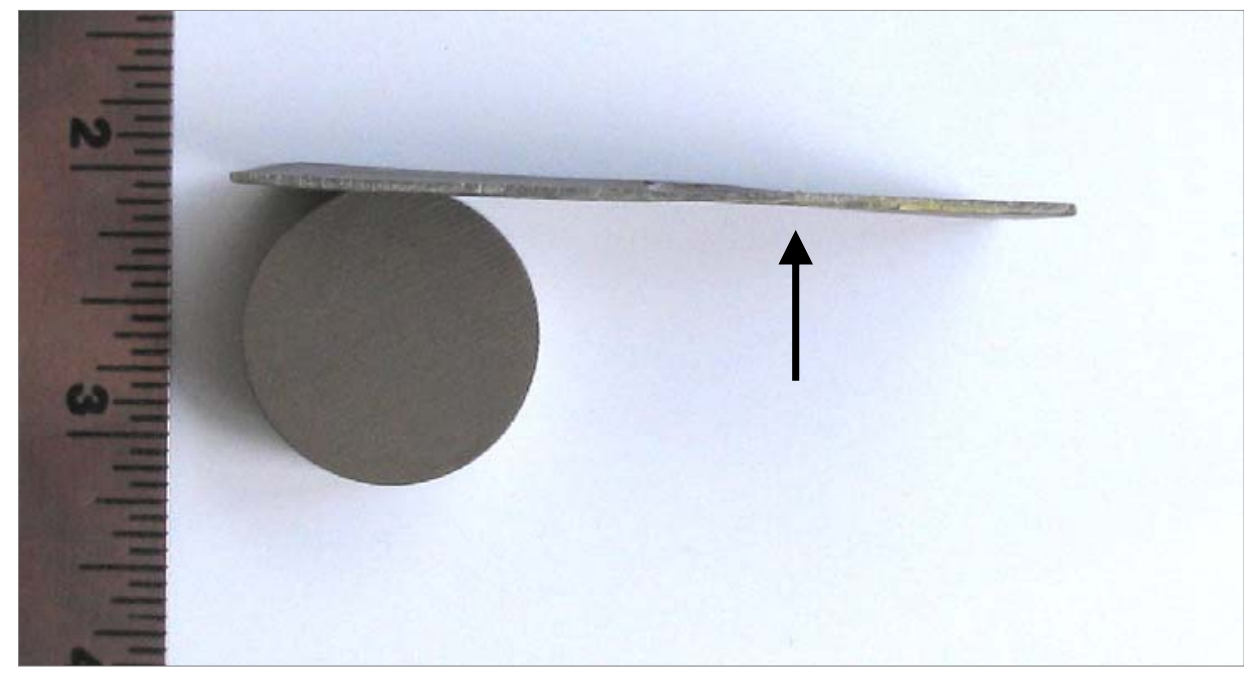

Figure 12. Digital images showing the bead-on-plate weld zone obtained by FSW on the $0.1 \mathrm{~cm}$ thick plate of 14YWT. The image in (a) shows the top view and in (b) the near edge view of the thin plate. Note: the arrow in Fig. 12b shows the location of the bead-on-plate weld zone. 
The microstructural characterization study of the FSW bead-on-plate weld zone of the thin plate of 14YWT will now be initiated. The approach will be to prepare a cross-section sample from the thin plate by cutting a sample from the side containing the bead-on-plate weld zone, then mounting and polishing it using metallographic procedures. The sample will first be examined using the SEM from which regions of interest in the microstructure will be chosen to have one or more TEM specimens produced by the liftout/FIB method. The microstructural analysis of the polished sample and the TEM specimen(s) will focus on changes in grain size and the size, number density and composition of the oxygen-enriched nanoclusters by comparing with the results obtained in the reference microstructural characterization study.

\section{SUMMARY}

Friction stir welding was investigated as a method to join thin plate and thin wall tubing of 14YWT, which is being developed for advanced fuel cladding for sodium fast reactors. In the first FSW attempt, a $1.06 \mathrm{~cm}$ thick plate of $14 \mathrm{YWT}$ (SM13 heat) was successfully rolled at $1000^{\circ} \mathrm{C}$ to the target thickness of $0.1 \mathrm{~cm}$ thickness with no edge cracking. This achievement is a highlight since previous attempts to roll 14YWT plates have resulted in extensive cracking. For the FSW run, a proprietary pin tool design developed by the ORNL FSW Process Development effort was used. The first FSW run successfully produced a bead-on-plate weld zone in the $0.1 \mathrm{~cm}$ thick plate. The weld zone showed good mixing as evidence of the swirl pattern on the top surface of the plate with no evidence that defects such as cavities formed. The microstructural characterization study of the bead-on-plate weld zone will be initiated to compare the results of the microstructure analysis with those obtained in the reference microstructural analysis of the $1.06 \mathrm{~cm}$ thick plate of 14YWT (SM13 heat) that showed ultra-fine grain size of $0.43 \mu \mathrm{m}$ and a high number density of $\sim 2-5 \mathrm{~nm}$ size oxygen-enriched nanoclusters. Nevertheless, the results of this study indicate that FSW looks promising as a method to join thin sections of ODS ferritic alloys.

\section{REFERENCES}

[1] W.M. Thomas, E.D. Nicholas, J.C. Needham, M.G. Murch, P. Templesmith, C.J. Dawes, G.B. Patent Application No. 9125978.8, (1991).

[2] R.S. Mishra, Z.Y. Ma, Materials Science and Engineering R, 50, (2005), 1-78.

[3] S.M. Howard, B.K. Jasthi, W.J. Arbegast, G.J. Grant, S. Koduri, D.R. Herling, D.S. Gelles, DOE/ER0313/37, (2004), 55-60.

[4] P. Miao, G.R. Odette, J. Gould, J. Bernath, R. Miller, M. Alinger, C. Zanis, Journal of Nuclear Materials, 367-370, (2007), 1197-1202.

[5] Z. Feng, W. Ren, Initial development in joining of ODS alloys using friction stir welding, ORNL/GEN4/LTR-06-021, (2006).

[6] Z. Feng, W. Ren, ASME PVP Conference, paper no PVP200726663, (2007).

[7] G.J. Grant, D.S. Gelles, R.J. Steel, R. Lindau, DOE/ER-0313/38, (2005), 47-53.

[8] F. Legendre, S. Poissonnet, P. Bonnaillie, L. Boulanger, L. Forest, Journal of Nuclear Materials, 386388, (2009), 537-539.

[9] D.T. Hoelzer, K.A. Unocic, M.A. Sokolov and Z. Feng, Journal of Nuclear Materials, 442, (2013), 529-534. 